\title{
EFEITOS DO USO DE ADITIVO COM NANOSÍLICA EM SUSPENSÃO COLOIDAL NA CONSISTÊNCIA E RESISTÊNCIA MECÂNICA DO CONCRETO
}

\author{
Effects of using chemical admixture with nanosilica in the consistence and \\ mechanical strength of concrete
}

\author{
Tiago Ferreira Campos Neto ${ }^{1}$, André Luiz Bortolacci Geyer ${ }^{2}$
}

Recebido em 09 de março de 2017; recebido para revisão em 20 de abril de 2017; aceito em 02 de maio de 2017; disponivel on-line em 16 de maio de 2017.

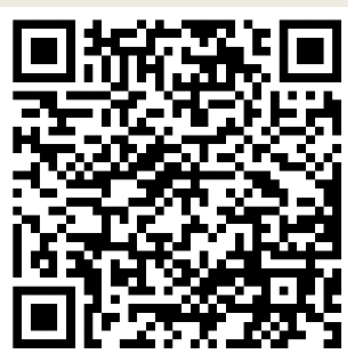

PALAVRAS CHAVE:

Concreto;

Aditivo superplastificante;

Nanosílica;

Consistência;

Resistência dos materiais.

\section{KEYWORDS:}

Concrete;

Superplasticizer

admixture;

Nanosilica;

Consistence;

Mechanical strength.

RESUMO: O desempenho do concreto depende do seu comportamento nos estados fresco e endurecido. Geralmente, estudos de misturas com nanosílica (nS) são voltados para análise do desempenho no estado endurecido e são fundados no uso da adição mineral em grãos secos. Dessa forma, este artigo tem o objetivo de avaliar os efeitos do uso de aditivo superplastificante com nanosílica em suspensão coloidal na consistência e resistência mecânica do concreto. Foram dosadas duas misturas com mesmos materiais e traços idênticos, no entanto com aditivos superplastificantes diferentes, sendo um incorporado com nanosílica e outro sem a adição mineral. A mistura sem nanosílica (CC) foi usada como referência de estudo para análise dos efeitos da presença da nanosílica na outra mistura (CnS), tanto na evolução da consistência como na resistência mecânica do concreto. Para avaliação dessas propriedades foram realizados ensaios de perda de abatimento em função do tempo e resistência à compressão aos 28 dias. Os resultados mostraram que o concreto dosado com aditivo sem nanosílica apresentou maior tempo disponível para manuseio, bem como maiores valores de abatimento durante todo o ensaio. Entretanto, o concreto com aditivo com nanosílica apresentou melhor desempenho no estado endurecido, atingindo maior valor de resistência mecânica.

ABSTRACT: The concrete's performance depends on its behavior in the fresh and hardened states. Generally, studies of nanosilica (nS) are focused on performance analysis in the hardened state and they are founded on the use of the mineral admixture in dry grains. Thus, this paper aims to evaluate the effects of superplasticizer admixture use with nanosilica in colloidal suspension in the consistency and strength of the concrete. Two mixtures were produced with the same materials and identical proportions, however with different superplasticizes, one with and the other without nanosilica. The mixture without nanosilica (CC) was used as reference to analyse the effects of the presence of mineral admixture in the other mixture (CnS), both in the development of the consistency and the mechanical strength of the concrete. For evaluation of these properties were carried slump tests as a function of time and compressive strength at 28 days. The results showed that the concrete without nanosilica presented greater time available for handling and also higher slump values throughout the test. However, the concrete with the superplasticizer with nanosilica performed better in the hardened state, reaching highest mechanical strength.

* Contato com os autores:

${ }^{1}$ e-mail: tiagocampos.eng@gmail.com (T. F. Campos Neto )

Eng. Civil, Mestre em Engenharia Civil, Docente na Universidade de Rio Verde (UNIRV).

${ }^{2}$ e-mail: andre.geyer@hotmail.com ( A. L. B. Geyer )

Eng. Civil, Doutor em Engenharia Civil, Docente da Escola de Engenharia Civil e Ambiental - Universidade Federal de Goiás (UFG). 


\section{INTRODUÇÃO}

O concreto fresco enrijece com o tempo, especialmente se for misturado continuamente. $\mathrm{O}$ resultado de uma mistura prolongada está associado à perda de abatimento acelerada do concreto. A perda de trabalhabilidade do concreto pode criar uma série de problemas incluindo dificuldade de lançamento e adensamento, resultando em um concreto mais poroso e com baixa resistência mecânica e durabilidade (SOROKA; RAVINA, 1998).

As propriedades relacionadas à trabalhabilidade incluem consistência, segregação, exsudação, mobilidade, bombeamento e acabamento. A consistência é considerada um indicador mais próximo da trabalhabilidade, isto é, é um parâmetro que mensura a facilidade de escoamento e coesão da mistura. O abatimento é usado como uma medida da consistência do concreto (KOSMATKA; KERKHOFF; PANARESE, 2003).

A nanotecnologia foi definida por Drexler, Peterson e Pergamit ${ }^{1}$ (1991 apud SAID et al., 2012) como "o controle da estrutura da matéria com base no controle de molécula por molécula dos produtos e subprodutos". A nanotecnologia pode ser considerada como um dos temas mais modernos nas áreas da ciência e tecnologia. Por ter grande potencial de mercado e impacto econômico, a necessidade de exploração neste campo e suas aplicações têm crescido significativamente nas últimas décadas.

Atualmente, há um grande número de aplicações da nanotecnologia no campo da construção civil. $O$ estudo dos nanomateriais é um crescente campo que tem atraído interesse e tem sido aplicado em questões que vão desde a fabricação de novos produtos até a busca por novas aplicações. Assim, é fundamental que sejam estudadas suas propriedades físicas e químicas, além do seu comportamento junto às misturas com

1 DREXLER, K. E.; PETERSON, C.; PERGAMIT, G. Unbounding the future: the nanotechnology revolution. New York: William Morrow, 1991.

${ }^{2}$ NILI, M.; EHSANI, A.; SHABANI, K. Influence of nano-SiO2 outros materiais.

Um dos produtos mais utilizados é a nanosílica (nS) e, mesmo sendo largamente utilizada, suas aplicações e efeitos sobre as misturas de concreto ainda não são completamente conhecidos. Segundo Nili, Ehsani e Shabani ${ }^{2}$ (2010 apud QUERCIA et al., 2012), a nanosílica é capaz de aumentar a resistência à compressão e reduzir a permeabilidade total do concreto endurecido.

\subsection{OBJETIVO}

Sabe-se que o desempenho do concreto depende do seu comportamento tanto no estado endurecido como no estado fresco. A maioria dos estudos de concretos com nanosílica é voltada para a análise dos impactos na mistura já endurecida e pouco se sabe sobre os impactos na mistura fresca. Além disso, os estudos, também em sua maioria, são fundamentados na adição de nanosílica em grãos secos. Dessa forma, este artigo tem o objetivo de avaliar os efeitos da adição aditivo superplastificante com nanosílica, em suspensão coloidal, na consistência e resistência mecânica do concreto.

\section{NANOSÍLICA E O CONCRETO}

O concreto é um material usado em infraestruturas e edifícios. Ele é composto por materiais granulares de diferentes tamanhos. A graduação total da mistura, que contem partículas de $300 \mathrm{~nm}$ a $32 \mathrm{~mm}$ determina as propriedades do concreto. As propriedades no estado fresco são, por exemplo, reguladas pela distribuição dessas partículas de diferentes tamanhos, mas as propriedades no estado endurecido, tais como resistência e durabilidade, também são afetadas pelo empacotamento resultante das partículas. Uma forma de melhorar o empacotamento é aumentar a gama de tamanhos dos grãos, por exemplo, incluindo partículas com dimensões

and micro-silica on concrete performance. In: International Conference on Sustainable Construction Materials and Technologies. 2., jun, 2010. Anais... Universita Ploitecnica delle Marche, Ancona, Itália, 2010. 
inferiores a $30 \mathrm{~nm}$. Alguns materiais têm sido largamente utilizados, tais como, sílica ativa e nanosílica (QUERCIA; BROUWERS, 2010).

$O$ desenvolvimento de novas tecnologias para concreto resulta da emergência de uma nova ciência dos materiais cimentícios, uma nova ciência de aditivos e adições e uso de equipamentos científicos sofisticados para caracterizar a microestrutura e até a nanoestrutura. Para Zhu, Bartos e Porro ${ }^{3}$ (2004 apud GLEIZE, 2011), a utilização de nanomateriais ao concreto permite não só um melhor controle de sua microestrutura, o que não permitem as tecnologias atuais, como também a produção de materiais mais duráveis e resistentes.

Segundo Kim et al. (2013), o principal produto de hidratação do cimento e que compõe aproximadamente $67 \%$ do produto hidratado é o silicato de cálcio hidratado (C-S-H). Esse produto de hidratação pode ser alterado pela incorporação de nanopartículas. Sabe-se que a zona de transição da interface agregado-pasta de cimento hidratada é a região mais frágil do concreto, no entanto ela pode ser reduzida por meio da adição de materiais pozolânicos na mistura do concreto. As pozolanas são capazes de consumir sólidos presentes na zona de transição, por exemplo o hidróxido de cálcio $(\mathrm{CH})$, nas reações pozolânicas aumentando as quantidades de C-S-H e reduzindo a espessura da zona da película.

Said et al. (2012) enunciam que a nS pode se apresentar de duas formas: grãos secos compactados ou em suspensão coloidal. Os grãos secos de nS devem passar por um procedimento de preparação especial antes de serem inseridos na mistura de concreto, assim é garantida a completa dispersão na água de amassamento ou no aditivo. Por outro lado, a nanosílica em suspensão coloidal, produzida como uma suspensão estabilizada por um agente dispersor, é uma forma já pronta para uso.

${ }^{3}$ ZHU, W.; BARTOS, P. J.; PORRO, A. Application of nanotechnology in construction. Materials and Structures, v. 37, p. 649-658, 2004.

4 CAMPILLO, I.; DOLADO, J. S.; PORRO, A. Highperformance nanostructured materials for construction. In: International Symposium on Nanotechnology in
Campillo, Dolado e Porro ${ }^{4}$ (2003 apud SAID et al., 2012) estudaram as propriedades de argamassas dosadas com as duas diferentes formas $e$ concluíram que o comportamento das misturas incorporadas com nS em suspensão coloidal foi melhor e atribuíram tal resultado à melhor dispersão com alta redução de aglomeração em comparação à nS em grãos secos.

Diferentes efeitos são produzidos no concreto pela adição de nanosílica ou sílica ativa. A adição de sílica ativa diminui a quantidade de cimento necessária, sendo este um efeito mais pronunciado para a nS. O principal mecanismo deste princípio de trabalho é a elevada superfície específica, que atua como pontos de nucleação para a precipitação do gel de C-S-H (QUERCIA; BROUWERS, 2010). Bjornstrom et al. ${ }^{5}$ (2004 apud BASTAMI; BAGHBADRANI; ASLANI, 2014) afirmam que ainda não está claro se a aceleração no processo de hidratação do cimento na presença de nS é causada pela sua reatividade pozolânica mediante dissolução ou pelo aumento da superfície específica. Resultados de testes de viscosidade têm mostrado que pastas de cimento ou argamassas com nS exigem mais água para manter a trabalhabilidade. Além disso, a nanosílica apresenta uma forte tendência à adsorção iônica em meio aquoso, logo a formação de aglomerados é esperada. Neste último caso, aditivos plastificantes são indicados.

Em geral, a sílica ativa concorre para retardar a reação exotérmica do cimento, além de reduzir a permeabilidade do concreto. Concretos com sílica ativa têm o processo de hidratação retardado devido às partículas em hidratação estarem mais separadas pela presença da adição mineral e, o fluxo de calor é mais baixo, sendo proporcional ao teor de clínquer presente. No

Construction. 1., 2003. Anais... Paisley, Escócia, 2003.

5 BJORNSTROM, J.; MARTINELLI, J.; MATIC, A.; BORJESSON, L.; PANAS, I. Accelerating effects of coloidal nano-Silica for beneficial calcium-silicate-hydrate formation in cement. Chemical Physics Letters, v. 392, n. 1-3, p. 242-248, jul, 2004. 
entanto, Belkowitz e Armentrout ${ }^{6}$ (2009 apud SAID et al., 2012) investigaram os efeitos da nS no processo de hidratação do cimento e constataram que o pequeno tamanho das partículas fornece uma maior superfície de contato, que acelera a taxa de hidratação do cimento e as reações pozolânicas.

El-Baky, Yehia e Khalil (2013) avaliaram o desempenho de argamassas de cimento Portland no estado fresco incorporadas com nanosílica em grãos. A nS com dimensão de $19 \mathrm{~nm}$ foi utilizada com uma adição em substituição ao cimento em teores de $0,1,3,5,7$ e 10\%; a relação água/aglomerante (a/ag) foi mantida constante e igual a 0,48; e a proporção de areia foi de 2,75 em função do cimento. Os ensaios de fluidez das diferentes argamassas foram realizados de acordo com a ASTM C1437 (Standart Test Method for Flow of Hydraulic Cement Mortar) e os resultados mostraram que a redução da fluidez é proporcional ao aumento da porcentagem de nS na mistura até $7 \%$, visto que parte da água de amassamento foi utilizada na ativação das partículas da adição devido à sua elevada superfície específica. No entanto, esse comportamento é alterado quando o teor de nS atinge $10 \%$, onde a fluidez volta a aumentar devido ao excesso de nanopartículas. Assim, em teores menores, a nS absorve parte da água da mistura, reduzindo a consistência das argamassas, enquanto que em teores maiores, a nanosílica que não reage atua como um lubrificante, aumentando novamente a fluidez da mistura. A Figura 1 apresenta os resultados de fluidez das misturas.

Ainda no mesmo estudo, os pesquisadores realizaram micrografias com microscópio eletrônico de varredura (MEV) nas misturas de argamassa sem adição (convencional) e com $7 \%$ de nS. Os resultados apontaram que a argamassa com nanosílica é mais densa e homogênea do que a convencional. Os pesquisadores atribuíram esse resultado às reações pozolânicas, resultando em maior coesão, entretanto apresentando menor trabalhabilidade do que a argamassa convencional.

${ }^{6}$ BELKOWITZ, J.; ARMENTROUT, D. L. The investigation of nano-silica in the cement hydration process. ACl Special

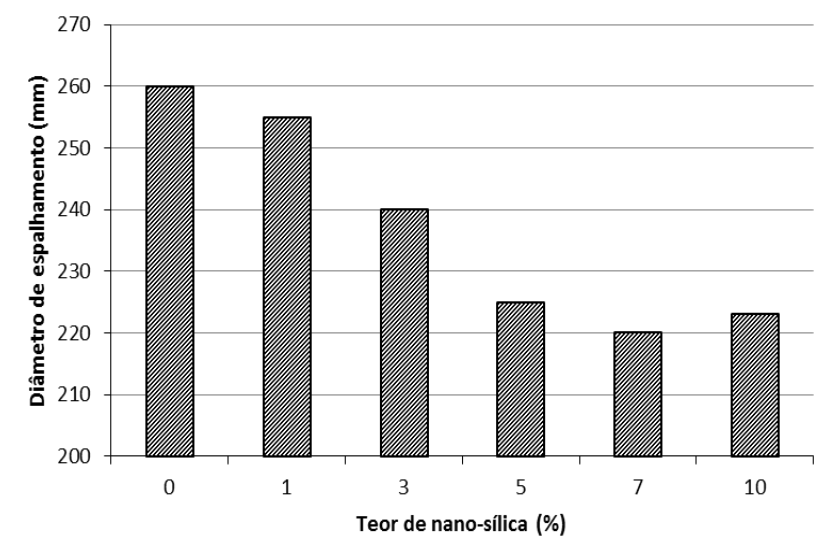

FIGURA 1: Fluidez de argamassas com diferentes teores de $\mathrm{nS}$.

FONTE: Adaptado de EL-BAKY; YEHIA; KHALIL, 2013.

Em se tratando de desempenho mecânico, Said et al. (2012) estudaram concretos dosados com diferentes teores de nanosílica $(0 \%, 3 \%$ e $6 \%$ ) em suspensão coloidal. Três concretos foram dosados sem cinza volante e três concretos foram dosados com cinza volante classe $F$, conforme especificado pela ASTM C 618 (Standart Specification for Coal Fly Ash and Raw or Calcined Natural Pozzola for Use in Concrete). O consumo de material cimentício foi mantido constante $\left(390 \mathrm{~kg} / \mathrm{m}^{3}\right)$, assim como a relação água/materiais cimentícios $(0,40)$. Foram avaliadas as propriedades de resistência mecânica, permeabilidade e porosidade dos concretos. Os resultados apontaram que os corpos-de-prova com adição de nS obtiveram os maiores valores de resistência à compressão e que a adição de cinza volante em conjunto com a nS pode reduzir a evolução da resistência mecânica dos concretos a longo prazo. A Figura 2 apresenta a evolução das resistências à compressão dos concretos estudados, onde o Grupo A é constituído por concretos sem cinza volante e o Grupo B com a adição mineral.

A permeabilidade foi analisada por meio do ensaio de penetração de cloretos por imersão, que determina a profundidade da penetração dos cloretos por meio do método do colorímetro regulamentado pela ASTM C 1202 (Standart Test Method for Electrical Indication of Concrete's Ability to Resist Chloride Ion Penetration). Por outro lado, 
a porosidade foi avaliada por meio do ensaio de porosimetria por injeção de mercúrio, que determina a porosidade total aparente do concreto e os diâmetros limiares dos poros. Os resultados de ambos os ensaios estão inseridos na Tabela 1.

Os concretos do grupo A incorporados com nS apresentaram menores índices de penetração por cloretos, chegando a atingir índice de permeabilidade $70 \%$ menor se comparado ao concreto sem a adição mineral. Já os concretos do grupo $B$, por serem acrescidos de cinza volante e $n S$, apresentaram uma redução menor e próxima a $60 \%$ do concreto sem nS. Na porosidade, os concretos com nS dos dois grupos apresentaram menores porosidades aparente e menores diâmetros limiares dos poros. Esses resultados constatam que a nanosílica atua não só como material pozolânico, mas também como fíler nas misturas.

Kim et al. (2013) analisaram os efeitos da nanosílica na composição de concretos curados sob diferentes condições de temperatura. Foram estudados três concretos com teores de 0,1 e $3 \%$ de nS, curados por sete dias em diferentes condições de temperatura $\left(20^{\circ} \mathrm{C}\right.$ e $\left.38^{\circ} \mathrm{C}\right)$. O objetivo foi avaliar o grau de hidratação do cimento e a reatividade pozolânica relativa da adição mineral. Os resultados evidenciaram uma acelerada hidratação do cimento em condições de elevada temperatura e que a fração de nS que participou ativamente na reação pozolânica é maior quando a pasta de cimento é submetida a altas temperaturas.

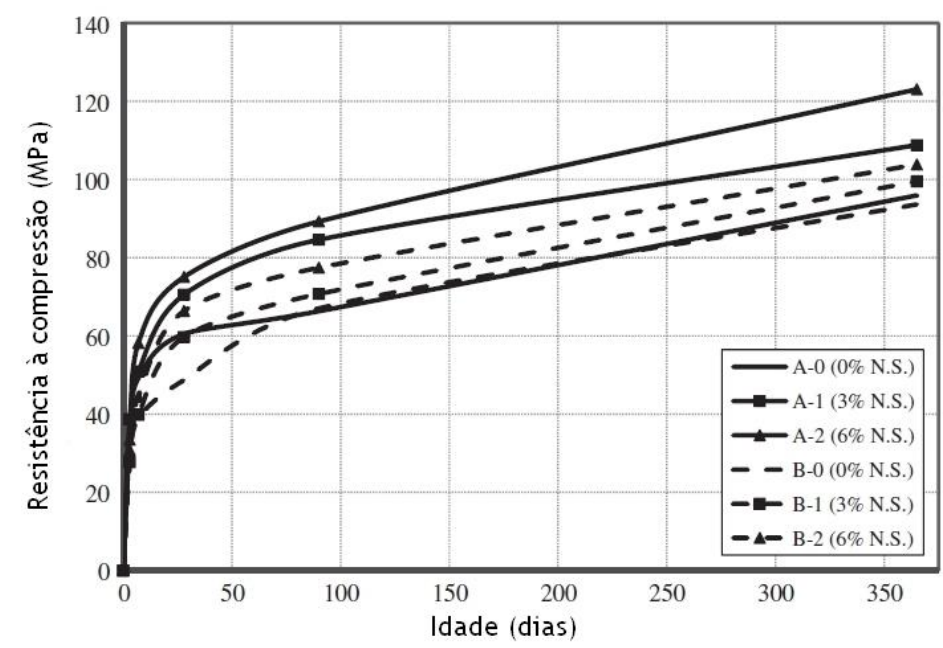

FIGURA 2: Evolução das resistências à compressão dos concretos. FONTE: Adaptado de SAID et al., 2012.

TABELA 1: Índices de permeabilidade e porosidade dos concretos.

\begin{tabular}{c|c|c|c|c}
\multirow{2}{*}{ Mistura } & \multicolumn{2}{|c|}{ Permeabilidade } & \multicolumn{2}{c}{ Porosidade } \\
\cline { 2 - 5 } & $\begin{array}{c}\text { Profundidade } \\
\text { média de } \\
\text { penetração }(\mathbf{m m})\end{array}$ & $\begin{array}{c}\text { Classe de } \\
\text { penetrabilidade } \\
\text { (ASTM C 1202) }\end{array}$ & $\begin{array}{c}\text { Porosidade } \\
\text { total aparente } \\
\mathbf{( \% )}\end{array}$ & $\begin{array}{c}\text { Diâmetro limiar } \\
\text { dos poros }(\boldsymbol{\mu} \mathbf{m})\end{array}$ \\
\hline A-0 $(0 \% \mathrm{nS})$ & 10,2 & Baixa & 10,13 & 0,100 \\
A-1 $(3 \% \mathrm{nS})$ & 3,1 & Muito baixa & 6,91 & 0,075 \\
A-2 $(6 \% \mathrm{nS})$ & 4,6 & Muito baixa & 6,44 & 0,060 \\
B-0 $(0 \% \mathrm{nS})$ & 8,1 & Muito baixa & 12,56 & 0,144 \\
B-1 (3\% nS) & 4,1 & Muito baixa & 9,30 & 0,092 \\
B-2 $(6 \% \mathrm{nS})$ & 3,3 & Muito baixa & 8,21 & 0,075 \\
\hline
\end{tabular}

FONTE: Adaptado de SAID et al., 2012. 


\section{CONSISTÊNCIA E RESISTÊNCIA MECÂNICA DO CONCRETO}

A seleção dos materiais apropriados e a dosagem são passos importantes para produzir um concreto que atenda às especificações de resistência e durabilidade na estrutura. Esse objetivo, no entanto, pode não ser atingido se uma atenção adequada não for dada às operações às quais o concreto é submetido nas primeiras idades. O termo "primeiras idades" abrange apenas um insignificante intervalo de tempo, por exemplo, os dois primeiros dias após a produção, no total da expectativa de vida útil do concreto, mas durante esse período numerosas operações são realizadas, tais como mistura, transporte até o local de aplicação, lançamento nas fôrmas, adensamento, acabamento, cura e desmoldagem. Estas operações são influenciadas pelas características do concreto fresco, por exemplo: trabalhabilidade, tempo de pega e maturidade ou taxa de crescimento da resistência. Evidentemente, o controle simultâneo das operações nas primeiras idades e das propriedades do concreto fresco é essencial para assegurar que o elemento de concreto acabado seja estruturalmente adequado para a finalidade para a qual foi projetado (MEHTA; MONTEIRO, 2014). O período da primeira idade na vida do concreto é insignificantemente pequeno se comparado ao total de sua expectativa de vida, mas durante esse período ele está sujeito a muitas operações que não somente são afetadas pelas propriedades do material, mas também as influenciam. Por exemplo, um concreto com pouca trabalhabilidade pode ser difícil de misturar; por outro lado, um tempo de mistura excessivo pode reduzir a trabalhabilidade.

Para uma relação a/c constante, um aumento na relação agregado/cimento irá reduzir a trabalhabilidade e, consequentemente, mais cimento será necessário. A deficiência de agregado miúdo resulta em uma mistura mais áspera, propícia à segregação e difícil acabamento, por outro lado, o excesso de agregado miúdo resulta em uma mistura mais permeável e menos econômica e durável, porém mais facilmente trabalhável (MINDESS; YOUNG, 1981). Partículas mais finas requerem mais água para molhagem de sua grande superfície específica, enquanto a forma irregular e textura rugosa de um agregado anguloso demandam mais água que um agregado arredondado. As adições minerais inseridas com o objetivo de substituir parte do cimento têm pequeno impacto na trabalhabilidade, aumentando a coesão da mistura.

O tempo e a velocidade de mistura podem prejudicar a trabalhabilidade de qualquer concreto. A Designação C 94 (ASTM, 2015) afirma que misturar em velocidades elevadas e por longos períodos, aproximadamente uma hora ou mais, pode resultar em perdas de resistência mecânica, aumento de temperatura da mistura, perda excessiva do ar incorporado e perda acelerada de abatimento.

Os aditivos superplastificantes, um dos mais utilizados pela indústria do concreto, são responsáveis por garantir alta fluidez às misturas, no entanto Tutikian e Dal Molin (2008) afirmam que a maior dificuldade de uso desses aditivos é a taxa relativamente alta de perda de consistência com o tempo em comparação aos concretos convencionais, dificultando sua utilização em obras. Porém, nos casos em que um maior tempo de transporte e lançamento faz-se necessário, é indicada a especificação de abatimentos iniciais mais altos, que podem ser obtidos com o uso de aditivos plastificantes.

\section{MATERIAL E MÉTODOS}

\subsection{MATERIAL}

Para realização do procedimento experimental foram utilizados: cimento Portland $\mathrm{CP}$ II-F-40; sílica ativa, agregados miúdo e graúdo com duas granulometrias diferentes em si; aditivo multifuncional e aditivos superplastificantes de mesma base, sendo um deles com nanosílica em suspensão coloidal (Silicon NS AD 400) e o outro sem nS (Tec-Flow 50N). Os dados obtidos no processo de caracterização dos agregados e as especificações dos aditivos fornecidas pelos fabricantes estão apresentados na Tabela 2.

O traço utilizado na dosagem dos 
concretos foi fornecido por uma das maiores centrais de dosagem do estado de Goiás, sendo o mais comercializado pela empresa e mantido fixo em todas as misturas desta pesquisa. A ideia de se utilizar o traço mais comercializado na região parte do princípio de se trabalhar com misturas de composição próxima à de mercado, tornando a pesquisa mais aplicável às práticas das centrais de dosagem. Os traços unitários do concreto sem nanosílica (CC) e com nanosílica (CnS) estão apresentados na Tabela 3, sendo que os valores dos aditivos estão dispostos na forma de consumo em quilogramas por metro cúbico.

\section{TABELA 2: Caracterização dos agregados e especificações dos aditivos.}

\begin{tabular}{|c|c|c|c|c|}
\hline \multirow{2}{*}{ Característica } & \multicolumn{4}{|c|}{ Agregados } \\
\hline & Areia fina & Areia grossa & Brita '0' & Brita ' 1 ' \\
\hline $\begin{array}{c}\text { Massa unitária } \\
\left(\mathrm{kg} / \mathrm{dm}^{3}\right)\end{array}$ & 1,366 & 1,537 & 1,620 & 1,671 \\
\hline $\begin{array}{l}\text { Massa específica } \\
\left(\mathrm{kg} / \mathrm{dm}^{3}\right)\end{array}$ & 2,653 & 2,598 & 2,873 & 2,890 \\
\hline $\begin{array}{l}\text { Diâmetro máximo } \\
\text { característico }(\mathrm{mm})\end{array}$ & 0,60 & 4,75 & 12,50 & 25,00 \\
\hline Módulo de finura & 1,766 & 3,079 & 1,943 & 3,114 \\
\hline
\end{tabular}

\begin{tabular}{c|c|c|c}
\hline Característica & \multicolumn{2}{c}{ Aditivos } \\
& \multicolumn{2}{c}{ Tec-Mult 829 } & \multicolumn{2}{c}{ Tec-Flow 50N } & Silicon NS AD 400 \\
\hline Fabricante & RheoSet & RheoSet & Silicon \\
Aspecto / cor & $\begin{array}{c}\text { Líquido castanho } \\
\text { pH }\end{array}$ & $\begin{array}{c}\text { Líquido castanho } \\
\text { claro }\end{array}$ & Líquido mel escuro \\
Massa específica $\left(\mathbf{g} / \mathrm{cm}^{\mathbf{3}}\right)$ & $7,5 \pm 1,0$ & $6,0 \pm 1,0$ & $5,6 \pm 1,0$ \\
& $1,175 \pm 0,02$ & $1,110 \pm 0,02$ & $1,080 \pm 0,02$ \\
\hline
\end{tabular}

TABELA 3: Traço unitário das misturas.

\begin{tabular}{c|c|c|c|c|c|c|c|c|c} 
& Cimento & $\begin{array}{c}\text { Sílica } \\
\text { ativa }\end{array}$ & $\begin{array}{c}\text { Areia } \\
\text { fina }\end{array}$ & $\begin{array}{c}\text { Areia } \\
\text { grossa }\end{array}$ & $\begin{array}{c}\text { Brita 12,5 } \\
\mathbf{m m}\end{array}$ & $\begin{array}{c}\text { Brita } \\
\mathbf{2 5} \mathbf{~ m m}\end{array}$ & $\begin{array}{c}\text { Tec-Mult } \\
\mathbf{8 2 9}\end{array}$ & $\begin{array}{c}\text { Tec-Flow } \\
\mathbf{5 0 N}\end{array}$ & $\begin{array}{c}\text { Silicon NS } \\
\text { AD 400 }\end{array}$ \\
\hline $\begin{array}{c}\text { Concreto } \\
\text { sem nS } \\
\text { (CC) }\end{array}$ & 1 & 0,08 & 0,56 & 1,29 & 0,67 & 1,92 & 2,83 & 1,10 & - \\
$\begin{array}{c}\text { Concreto } \\
\text { com nS } \\
\text { (CnS) }\end{array}$ & 1 & 0,08 & 0,56 & 1,29 & 0,67 & 1,92 & 2,83 & - & 1,10 \\
\hline
\end{tabular}




\subsection{MÉTODOS}

Foram dosadas duas misturas com mesmos materiais e traços idênticos, no entanto com aditivos superplastificantes diferentes. Os aditivos possuem a mesma base (policarboxilatos), sendo um com adição de nanosílica em suspensão coloidal e outro sem a adição mineral. O concreto sem nS foi usado como referência de estudo para observação dos efeitos da presença da nanosílica na evolução da consistência e resistência mecânica do concreto. Para avaliação dessas propriedades foram realizados ensaios de perda de abatimento em função do tempo e resistência à compressão aos 28 dias.

Os ensaios de avaliação de perda de abatimento dos concretos foram realizados conforme regulamentação da NBR 10342 (ABNT, 2012), que apresenta a aparelhagem necessária, os requisitos e limites de temperatura e umidade do ar e o procedimento de execução do ensaio. Essa mesma norma especifica que o ensaio de abatimento pode ser encerrado quando o concreto atingir abatimento de $20 \pm 10 \mathrm{~mm}$ ou à critério da obra. Nesta pesquisa, o ensaio foi encerrado quando as misturas atingiram a classe de consistência S10 (abatimento menor que $50 \mathrm{~mm}$ ) de acordo com a NBR 7212 (ABNT, 2012) - evitando problemas na moldagem dos corpos-de-prova.

A NBR NM 67 (ABNT, 1998) foi utilizada como base para a determinação da consistência pelo abatimento do tronco de cone. Os corpos-de-prova foram moldados e curados de acordo com a NBR 5738 (ABNT, 2015) e submetidos a ensaios de resistência à compressão aos 28 dias conforme procedimento da NBR 5739 (ABNT, 2007).

\section{RESULTADOS E DISCUSSÕES}

Nesta pesquisa, o termo "tempo de trabalhabilidade" refere-se ao período contado a partir da primeira determinação do abatimento até o seu encerramento (50 $\pm 10 \mathrm{~mm}$ ). A Figura 3 apresenta os tempos de trabalhabilidade das misturas de concreto convencional (CC) e concreto com nanosílica (CnS).

Nota-se que o concreto dosado com nanosílica em suspensão coloidal, incorporada no aditivo superplastificante, apresentou tempo de trabalhabilidade menor do que o concreto sem a adição mineral. A redução no tempo disponível para manusear o concreto foi de quinze minutos e, essa diferença pode ser reflexo dos abatimentos iniciais atingidos pelos concretos, isto é, quinze minutos após a mistura dos materiais. El-Baky, Yehia e Khalil (2013) constataram que grande parte da água de amassamento é utilizada na ativação das partículas de nS devido à sua elevada superfície específica, reduzindo a fluidez inicial da mistura, conforme apresentado na Figura 4. O teor de nanosílica presente no aditivo superplastificante não foi informado pela empresa fabricante, entretanto, diante do resultado apresentado e fundamentandose nas conclusões de El-Baky, Yehia e Khalil (2013), observa-se que o teor de nS está abaixo de 10\%, colaborando com a redução da fluidez da mistura.

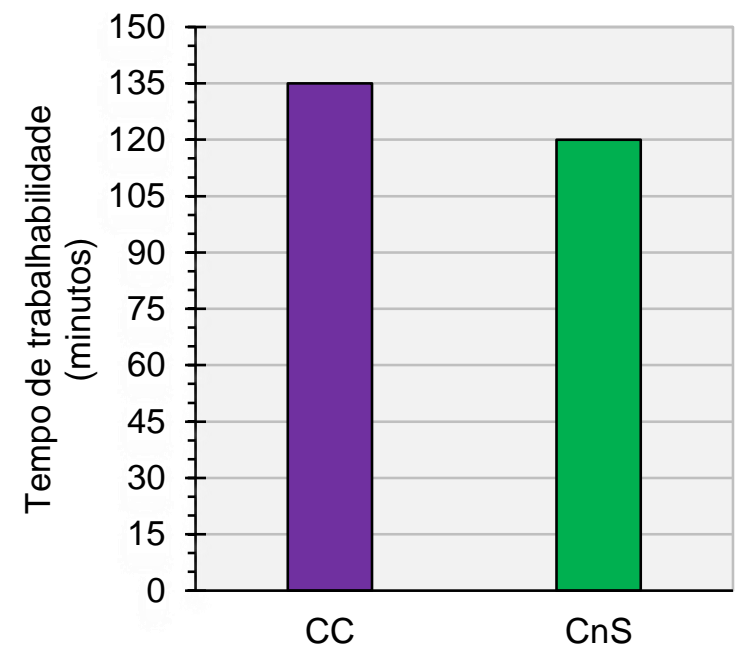

FIGURA 3: Tempo de trabalhabilidade das misturas. FONTE: Autoria própria.

A Figura 4 ainda apresenta as linhas limitantes das classes de consistência dos concretos conforme NBR 7212, (ABNT, 2012) e por apresentar menor abatimento inicial (190 mm), o concreto CnS apresentou-se na classe S160, ao passo que o concreto CC (225 mm) enquadrou-se à S220. É possível observar que a diferença de classe persistiu até a última determinação de abatimento, onde o CnS apresentou-se na classe S10, enquanto o CC no limite mínimo da S50.

No que diz respeito à evolução da 
consistência, os concretos apresentaram comportamentos semelhantes, sendo que o $\mathrm{CnS}$ apresentou menores valores em todas as determinações, fato possivelmente explicado pela maior demanda de água resultante da presença da nanosílica. Nota-se que as misturas apresentaram comportamentos lineares e descendentes. O CnS começou a perder consistência com mais rapidez após sessenta minutos, enquanto que o CC começou após 75 minutos, ou seja, mais uma vez a diferença de quinze minutos se manteve padrão.

Para avaliação do desempenho mecânico das misturas no estado endurecido foram moldados quatro corpos-de-prova para cada concreto. Os resultados estão apresentados na Figura 5, onde é possível constatar que o concreto incorporado com aditivo com nanosílica alcançou maior valor de resistência à compressão aos 28 dias. Esse resultado pode ser atribuído ao efeito pozolânico da nanosílica estudado e apresentado por Said et al. (2012).
De acordo com os valores de resistência à compressão atingidos, as duas misturas são categorizadas como concretos de alto desempenho, estando na classe de resistência do Grupo II da NBR 8953 (ABNT, 2015). No entanto, a mistura CnS, que atingiu 70,92 $\mathrm{MPa}$, pode ser classificada como classe C70; enquanto a mistura CC, que atingiu 65,57 MPa, está na classe $\mathrm{C60}$.

Em função da elevada superfície específica da nS, o valor da resistência mecânica do CnS poderia ter sido ainda maior, entretanto essa diferença se limitou a aproximadamente $5 \mathrm{MPa}$. Possivelmente, a falta de água de amassamento na mistura com nS pode ter colaborado com a não ativação das partículas de nS em suspensão coloidal, reduzindo o potencial pozolânico da adição mineral à quantidade de água disponível para as reações químicas. Futuramente, análises com modificações nas relações a/c podem ser feitas de forma a atestar a pozolanicidade do material e seu efeito no ganho de resistência mecânica.

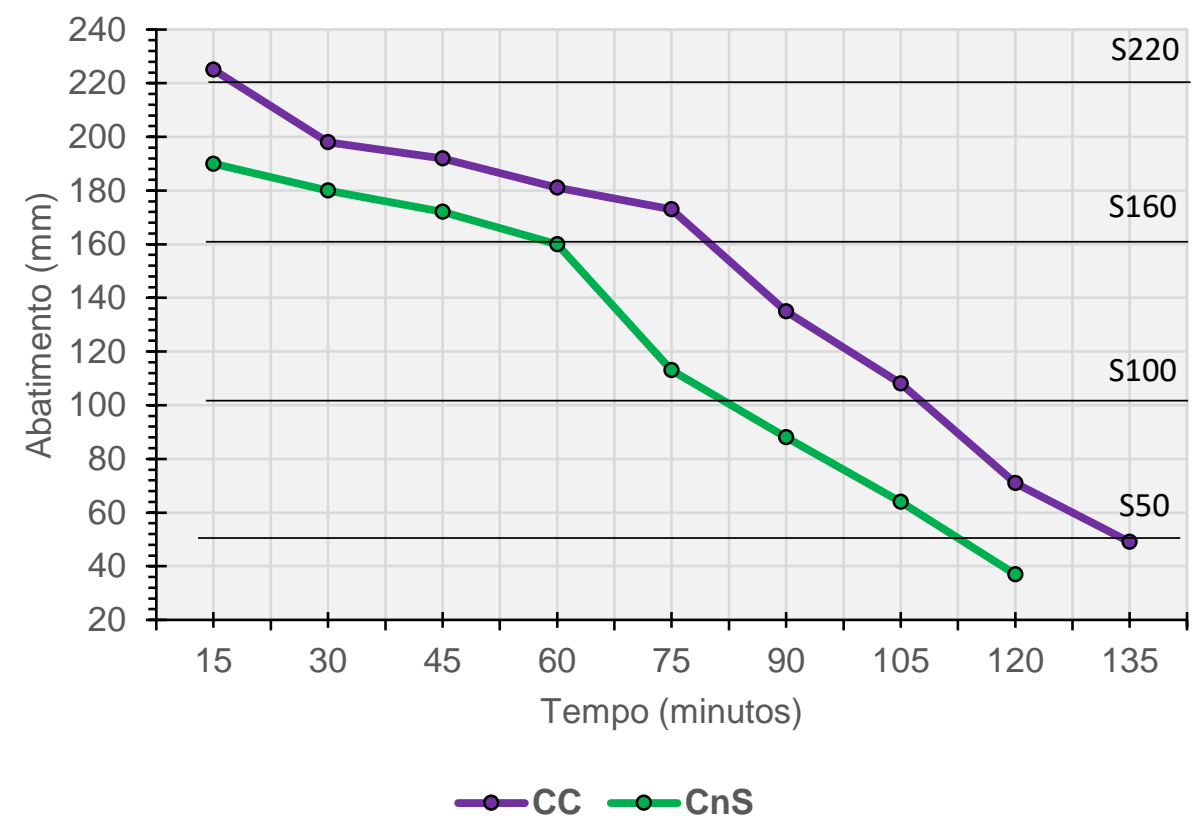

FIGURA 4: Evolução da consistência das misturas. FONTE: Autoria própria. 


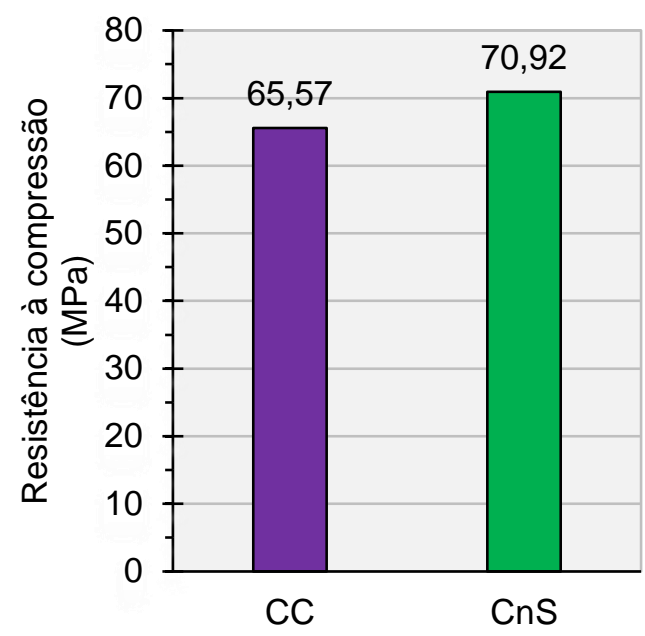

FIGURA 5: Resistência à compressão aos 28 dias. FONTE: Autoria própria.

\section{CONSIDERAÇÕES FINAIS}

Fundamentando-se nos resultados obtidos nesta pesquisa, é possível notar o efeito do aditivo superplastificantes com nanosílica em suspensão coloidal na consistência e resistência mecânica dos concretos. No estado fresco, os concretos incorporados com a adição mineral podem apresentar menores valores de abatimento se comparados aos concretos com aditivos sem nS. Esse fator pode reduzir os prazos de dosagem, transporte, lançamento e adensamento das misturas, sendo necessário avaliar a possibilidade de adequação da relação a/c ou uso de outro aditivo, como por exemplo, retardador de pega, no caso de concretagens com misturas dosadas em centrais.

No processo de evolução da consistência, os concretos apresentaram comportamento semelhante, ou seja, a presença da nanosílica não resultou em perdas excessivas de abatimento em função do tempo. No que diz respeito à resistência mecânica, a presença de nanosílica em suspensão coloidal no aditivo colaborou com o ganho de capacidade de carga do concreto, ampliando as possibilidades de aplicação da mistura.

Nas especificações do aditivo não é informado o teor de nanosílica presente em sua composição, no entanto ao comparar os resultados obtidos com pesquisas anteriores, acredita-se que esse teor esteja abaixo de 10\% (EL-BAKY; YEHIA;
KHALIL, 2013), pois a consistência da mistura foi prejudicada. Dessa forma, cabe aos fabricantes especificar o teor de nS presente na solução ou descrever criteriosamente os benefícios obtidos com o uso de determinado aditivo.

Por fim, nota-se que o aditivo com nanosílica em suspensão coloidal, mesmo reduzindo os valores de abatimento dos concretos, não influiu de maneira significativa na evolução da perda de consistência das misturas. Ao passo que o abatimento foi prejudicado, a resistência foi aprimorada com um ganho de aproximadamente $8 \%$, apontando a indicação do uso desse tipo de aditivo em concretos para fins estruturais.

\section{REFERÊNCIAS BIBLIOGRÁFICAS}

AMERICAN SOCIETY FOR TESTING AND MATERIALS. Designation C 494: Standart Specification for Chemical Admixtures for Concrete. West Conshohocken, Pensilvânia, 2013.

ASSOCIAÇÃO BRASILEIRA DE NORMAS TÉCNICAS. NBR 7212: Execução de concreto dosado em central. Rio de Janeiro, 2012

NBR 5738: Concreto - Procedimento para moldagem e cura de corpos de prova. Rio de Janeiro, 2015.

NBR 5739: Concreto - Ensaios de compressão de corpos-de-prova cilíndricos. Rio de Janeiro, 2007.

NBR 8953: Concreto para fins estruturais Classificação pela massa específica, por grupos de resistência e consistência. Rio de Janeiro, 2015. 
NBR 10342: Concreto - Perda de abatimento Método de ensaio. Rio de Janeiro, 2012.

NBR NM 67: Concreto - Determinação da consistência pelo abatimento do tronco de cone. Rio de Janeiro, 1998.

BASTAMI, M.; BAGHBADRANI, M.; ASLANI, F. Performance of nano-Silica modified high strength concrete at elevated temperatures. Cement and Building Materials, v. 68, n. 1, p. 402-408, 2014.

EL-KABY, S. ABD.; YEHIA, S.; KHALIL, I. S. Influence of nano-silica addition on properties of fresh and hardened cement mortar. In: INTERNATIONAL CONFERENCE ON NANOMATERIALS - RESEARCH AND APPLICATION, 5., 2013, Brno. Anais eletrônicos... Brno: Tanger, 2013. Disponível

em: <http://www.google.com.br/url?sa=t\&rct=j\&q=\&esrc=s \&source=web\&cd=10\&ved=0CGwQFjAJ\&url=http $\% 3 A \%$ 2F\%2Fwww.researchgate.net\%2Fpublictopics.PublicPost FileLoader.html\%3Fid\%3D52e3b135d4c1186f678b460e \%26key\%3D60b7d52e3b135e9bb4\&ei=SeEGVcesBsOXg wS5wYGgCA\&usg=AFQjCNG7ixVID2NqQ3Yfu2FLoX9Sem _sCg\&sig2=4gAlujZOe4fBju1MpFHqwQ>. Acesso em: 16 abr. 2016.

GLEIZE, P. J. P. Nanociência e Nanotecnologia dos Materiais Cimentícios. In: ISAIA, G. C. (Ed.) Concreto: Ciência e Tecnologia. 1. ed. São Paulo: IBRACON, n. 2, p. 1871-1884, 2011.

KIM, J. J.; RAHMAN, M. K.; AL-MAJED, A. A.; AL-ZAHRANI, M. M.; TAHA, M. M. R. Nanosilica effects on composition and silicate polymerization in hardened cement paste cured under high temperature and pressure. Cement and Concrete Research, v. 43, n. 1, p. 78-85, 2013.

KOSMATKA, S. H.; KERKHOFF, B.; PANARESE, W. C. Design and Control of Concrete Mixtures. 14. ed. Skokie: Portland Cement Association, 2003.

MEHTA, P. K.; MONTEIRO, P. J. M. Concreto: estrutura, propriedades e materiais. 2. ed. São Paulo: Pini, 2014.

MINDESS, S.; YOUNG, J. F. Concrete. New Jersey: Prentice-Hall Inc., 1981.

QUERCIA, G.; BROUWERS, H. J. H. Application of nanosilica ( $\mathrm{nS}$ ) in concrete mixtures. In: International PhD Symposium in Civil Engineering. 8., 2010, Kongens Lyngby. Anais eletrônicos... Kongens Lyngby: [s.n.]. 2010. Disponível em: <http://www.google.com.br/url?sa=t\&rct=j\&q=\&esrc=s \&source=web\&cd=1\&ved=0CCIQFjAA\&url=http $\% 3 \mathrm{~A} \% 2 \mathrm{~F}$ $\% 2 F w w w . r e s e a r c h g a t e . n e t \% 2 F p u b l i c a t i o n \% 2 F 22844256$ 9_Application_of_nano-

silica_\%2528nS\%2529_in_concrete_mixtures\%2Flinks\%2 F0c96052430c5abf699000000\&ei=nJuOVOTTNI_AgwTLk ILAAQ\&usg=AFQjCNGPrgaZMBEKIXeRu6pBjIMQcDUInA \&bvm=bv.81828268,d.eXY>. Acesso em: 22 abr. 2016.
QUERCIA, G.; SPIESZ, P.; HÜSKEN, G.; BROUWERS, J. Effects of amorphous nano-silica additions on mechanical and durability performance of SCC mixtures. In: INTERNATIONAL CONGRESS ON DURABILITY OF CONCRETE, 2012, Norway. Anais... Norway: ICDC, 2012.

SAID, A. M.; ZEIDAN, M. S.; BASSUONI, M. T.; TIAN, Y. Properties of concrete incorporating nano-silica. Construction and Building Materials, v. 36, n. 1, p. 838844, 2012.

SOROKA, I.; RAVINA, D. Hot Weather Concreting with Admixtures. Cement and Concrete Composites, v. 20, n. 2-3, p. 129-136, 1998 